\title{
Diverse Types of Interneurons Generate Thalamus-Evoked Feedforward Inhibition in the Mouse Barrel Cortex
}

\author{
James T. Porter, ${ }^{1}$ Cary K. Johnson, ${ }^{1}$ and Ariel Agmon ${ }^{1,2}$ \\ Department of ${ }^{1}$ Neurobiology and Anatomy and ${ }^{2}$ the Sensory Neuroscience Research Center, West Virginia University, \\ Morgantown, West Virginia 26506-9128
}

Sensory information, relayed through the thalamus, arrives in the neocortex as excitatory input, but rapidly induces strong disynaptic inhibition that constrains the cortical flow of excitation both spatially and temporally. This feedforward inhibition is generated by intracortical interneurons whose precise identity and properties were not known. To characterize interneurons generating feedforward inhibition, neurons in layers IV and V of mouse somatosensory ("barrel") cortex in vitro were tested in the cell-attached configuration for thalamocortically induced firing and in the whole-cell mode for synaptic responses. Identification as inhibitory or excitatory neurons was based on intrinsic firing patterns and on morphology revealed by intracellular staining. Thalamocortical stimulation evoked action potentials in $\sim 60 \%$ of inhibitory interneurons but in $<5 \%$ of excitatory neurons. The inhibitory interneurons that fired received fivefold larger thalamocortical inputs compared with nonfiring inhibitory or excitatory neurons. Thalamocortically evoked spikes in inhibitory interneurons followed at short la- tency the onset of excitatory monosynaptic responses in the same cells and slightly preceded the onset of inhibitory responses in nearby neurons, indicating their involvement in disynaptic inhibition. Both nonadapting (fast-spiking) and adapting (regular-spiking) inhibitory interneurons fired on thalamocortical stimulation, as did interneurons expressing parvalbumin, calbindin, or neither calcium-binding protein. Morphological analysis revealed that some interneurons might generate feedforward inhibition within their own layer IV barrel, whereas others may convey inhibition to upper layers, within their own or in adjacent columns. We conclude that feedforward inhibition is generated by diverse classes of interneurons, possibly serving different roles in the processing of incoming sensory information.

Key words: feedforward inhibition; thalamocortical; somatosensory cortex; barrel cortex; mice; parvalbumin; calbindin; FS cells; RSNP cells; spiny stellate cells; GABAergic interneurons
The mammalian neocortex is a densely interconnected neuronal network in which sensory information relayed via the thalamus is processed and transformed into conscious sensory perception, to be acted on or stored in memory, as needed. Although the thalamocortical input to the neocortex is purely excitatory (glutamatergic), as determined by electrophysiological, electron microscopic, and immunocytochemical evidence (White, 1978; Ferster and Lindstrom, 1983; Agmon and Connors, 1992; Kharazia and Weinberg, 1993), inhibitory (GABAergic) mechanisms are recruited from the very first stage of intracortical processing. Indeed, electrical stimulation of thalamocortical afferents in vivo (Ferster and Lindstrom, 1983; Swadlow, 1989, 1990) or in vitro (Agmon and Connors, 1992; Gil and Amitai, 1996), as well as controlled sensory stimulation (Simons and Carvell, 1989; Simons, 1995; Brumberg et al., 1996; Swadlow et al., 1998; Zhu and Connors, 1999), result in a brief excitation of neocortical neurons, immediately followed by a pronounced inhibitory response mediated by intracortical inhibitory interneurons. The short latency of the inhibitory response indicates that the inhibitory interneu-

Received Nov. 20, 2000; revised Jan. 22, 2001; accepted Jan. 31, 2001.

This work was supported by National Institutes of Health Grant HD33463. J.T.P. was supported by National Institutes of Health Grant NS10902. We thank Drs. Diane O'Dowd and George Spirou for a critical reading of an earlier version of this manuscript.

Correspondence should be addressed to Ariel Agmon, Department of Anatomy, P.O. Box 9128, West Virginia University, Morgantown, WV 26506-9128. E-mail: aagmon@wvu.edu.

Dr. Porter's present address: Department of Pharmacology and Toxicology, Ponce School of Medicine, P.O. Box 7004, Ponce, Puerto Rico 00732.

Copyright () 2001 Society for Neuroscience 0270-6474/01/212699-12\$15.00/0 rons eliciting it must be excited directly by the thalamocortical afferents, consistent with anatomical data (White, 1978; Fairén and Valverde, 1979; Freund et al., 1985; Keller and White, 1987), and in turn inhibit other cortical neurons disynaptically. This feedforward inhibition is a highly robust feature that can be engaged by even a single thalamocortical action potential (Swadlow and Gusev, 2000), can influence the spread of thalamocortically evoked excitation, and can shape the cortical representation of the sensory environment (Sillito, 1975; Tsumoto et al., 1979; Sillito et al., 1980; Hicks and Dykes, 1983; Dykes et al., 1984; Kyriazi et al., 1996; Kyriazi et al., 1998).

Intracortical inhibitory neurons are a diverse population (Cauli et al., 1997; Kawaguchi and Kubota, 1997; Gupta et al., 2000). Although they all use GABA as a neurotransmitter and have a nonpyramidal morphology with nonspiny or sparsely spiny dendrites, they vary considerably in other properties that may determine their effect on their postsynaptic targets. Different subpopulations of GABAergic interneurons contact postsynaptic neurons on different parts of their membrane (Somogyi, 1977; Jones and Hendry, 1984; Kawaguchi and Kubota, 1997; Tamas et al., 1997a), express different palettes of ionic channels resulting in different firing patterns (Cauli et al., 1997; Kawaguchi and Kubota, 1997; Porter et al., 1999), form synapses with very different temporal dynamics (Thomson et al., 1996; Reyes et al., 1998; Gupta et al., 2000), and exhibit different "spheres of influence", as reflected in the laminar and horizontal spread of their axonal arbors (Xiang et al., 1998). Our goal was to identify which of these diverse subpopulations were involved in mediating feedforward thalamo- 
Figure 1. Experimental setup. A, A low-magnification image of a fixed thalamocortical slice, illustrating typical placement of the stimulation microelectrode near the VB complexRTN border in the thalamus. The rectangular frame delineates the region of barrel cortex most likely to receive thalamocortical inputs in the slice (the dark blotches within this rectangle are three biocytin-filled inhibitory interneurons that fired in response to thalamocortical stimulation). $B$, The barrel cortex in a live thalamocortical slice, as visualized during the experiment by bright-field illumination. A field potential micropipette is inserted in a layer IV barrel (note the three barrels visible to the right of the micropipette tip). $C$, A high-power microscopic field from a layer IV barrel, as visualized during the experiment under DIC optics, showing a patch pipette (emphasized by the overlay) during a cell-attached and whole-cell recording from an inhibitory interneuron.
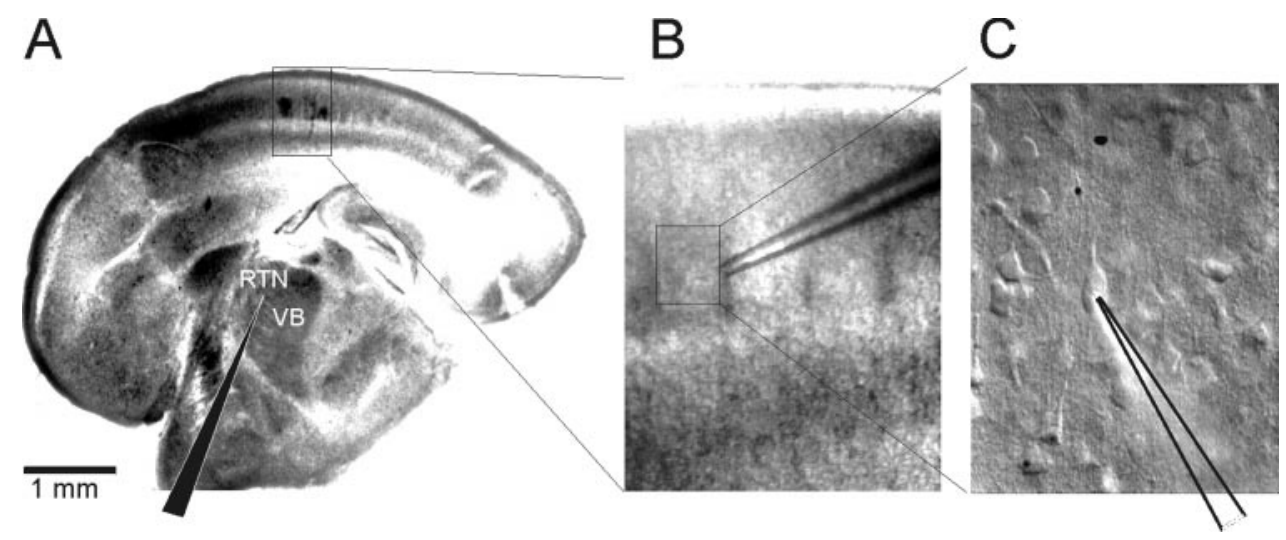

cortical inhibition. To do so, we tested inhibitory interneurons of the mouse barrel cortex for firing in response to thalamocortical stimulation in vitro, recorded their synaptic inputs and intrinsic firing patterns, characterized their cytochemical markers, and traced their dendritic and axonal morphologies. Our results indicate that thalamocortical feedforward inhibition is not the product of one specific subpopulation of interneurons, but rather the concerted effect of several distinct electrophysiological, cytochemical, and morphological classes.

\section{MATERIALS AND METHODS}

Preparation of thalamocortical brain slices. The procedure for preparing thalamocortical slices was modified from Agmon and Connors (1991). ICR white mice (postnatal days 9-18; Hilltop Lab Animals, Scottdale, PA) were anesthetized with methoxyflurane (Metofane; Mallinckrodt Veterinary, Mandelein, IL), decapitated, and their brains were removed into ice-cold artificial CSF (ACSF). The brain was dissected along the midline, and each hemisphere was placed with the midsagittal plane down on a circular glass coverslip, with the anterior pole pointing forward ("north"). The coverslip was then placed on a homemade sectioning platform, rotated horizontally $10^{\circ}$ to the right if the right hemisphere or to the left if the left hemisphere, and a cut was made at approximately one-third the distance from the anterior to the posterior pole, using a razor blade with its edge parallel to the east-west line and slanted $35^{\circ}$ northward. The razor blade was supported on a semicircular metal frame that could be rotated around the east-west axis, and both the $10^{\circ}$ and the $35^{\circ}$ angles were set using graduated circles printed on acetate film, cut out, and pasted to the sectioning platform in the horizontal and vertical (north-south) planes, respectively. This modification of the original method allowed preparation of thalamocortical slices from both hemispheres. The resultant block of tissue was glued with the anterior cut surface down onto a Vibroslicer stage (WPI, Sarasota, FL), and 300to $500-\mu \mathrm{m}$-thick slices were cut and examined by transillumination under a stereomicroscope. Slices containing both the ventrobasal thalamic complex (VB) and the barrel cortex were saved and incubated for $1 \mathrm{hr}$ at room temperature in ACSF containing (in $\mathrm{mM}$ ): $126 \mathrm{NaCl}, 3 \mathrm{KCl}, 1.25$ $\mathrm{NaH}_{2} \mathrm{PO}_{4}, 2.5 \mathrm{CaCl}_{2}, 1.3 \mathrm{MgSO}_{4}, 26 \mathrm{NaHCO}_{3}$, and 20 glucose, bubbled with carbogen $\left(95 \% \mathrm{O}_{2}\right.$ and $\left.5 \% \mathrm{CO}_{2}\right)$.

Extracellular recording and stimulation. Individual slices were transferred to a submersion recording chamber (Dagan Corporation, Minneapolis, MN) mounted on an Olympus BX50 upright microscope, and perfused with room temperature, carbogenated ACSF at a rate of 2-3 $\mathrm{ml} / \mathrm{min}$. The slices were placed with their anterior surface up, because intact thalamocortical axons are more likely to be near the anterior surface (Agmon et al., 1993). Bright-field illumination revealed the basic anatomical landmarks of the thalamocortical pathway, including individual layer IV barrels (Fig. 1A,B). To stimulate thalamocortical axons, a unipolar tungsten microelectrode (AM Systems, Carlsborg, WA) was placed in the $\mathrm{VB}$ or at the border of the VB and the reticular nucleus (RTN) (Fig. 1A), and $0.1 \mathrm{msec}$ cathodal current pulses of increasing intensity were elicited every $10-30 \mathrm{sec}$ using a Master-8 pulse generator and stimulus isolation unit (AMPI, Jerusalem, Israel). Field potentials were recorded with glass micropipettes $(1 \mathrm{~mm}$ outer diameter, $0.58 \mathrm{~mm}$ inner diameter; AM Systems) that were pulled on a Flaming-Brown pipette puller (Sutter Instruments, Novato, CA), slightly broken under a microscope, filled with $0.9 \% \mathrm{NaCl}$, and placed within a barrel "hollow" in layer IV (Fig. 1B). Field potentials were amplified $1000 \times$ (Intronix Technologies, Bolton, Ontario, Canada), low-pass-filtered at $1 \mathrm{kHz}$, and digitized at $2.5 \mathrm{kHz}$. The positions of the stimulating and recording micropipettes were adjusted to maximize the amplitude of the evoked field potential.

Cell-attached and whole-cell recording. Single neurons were visualized by infrared video-enhanced microscopy with differential interference contrast (DIC) optics (Stuart et al., 1993), using a Dage-MTI (San Diego, CA) CCD camera. To maximize the likelihood of recording from inhibitory interneurons, we targeted neurons with large, nonpyramidal appearing cell bodies (Simons and Woolsey, 1984; Lin et al., 1985) (Fig. $1 C)$. Cell-attached and whole-cell recordings in current-clamp and voltage-clamp modes were performed with a patch-clamp amplifier (Axopatch 200A; Axon Instruments, Foster City, CA). Patch pipettes (3-5 $\mathrm{M} \Omega$ ), pulled from high-lead content glass capillaries (Corning \#0010 glass; WPI), were filled with an internal solution containing (in mM): 136 $\mathrm{K}$ methylsulfate, $2 \mathrm{MgCl}_{2}, 0.6$ EGTA, and 10 HEPES, pH 7.2, 285-295 mOsm, for current-clamp experiments, or with: 122 Cs gluconate, 2 $\mathrm{MgSO}_{4}, 0.6$ EGTA, 10 HEPES, 0.1 Spermine, and 10 QX-314, pH 7.2, 285-295 mOsm, for voltage-clamp experiments in which the synaptic responses were recorded at depolarized potentials. Current or voltage pulse protocols were generated with the Master- 8 pulse generator. After achieving a cell-attached configuration, the thalamocortical fibers were stimulated with increasing intensity, until spikes were evoked or up to a maximum of $200 \mu \mathrm{A}$. (The $200 \mu \mathrm{A}$ cap on the intensity of the stimulation was chosen because pilot experiments indicated that further increase in stimulus intensity was unlikely to increase the probability of firing; the majority $(62 \%, n=60)$ of discharging cells fired at an intensity $\leq 120$ $\mu \mathrm{A}$.) The seal was then ruptured, and a whole-cell configuration was established. Resting membrane potential was measured just after achieving the whole-cell configuration, and only cells with a resting membrane potential more negative than $-50 \mathrm{mV}$ were analyzed. The intrinsic firing pattern of the neurons was tested by applying depolarizing current steps in the current-clamp mode. In some neurons, recorded with the Csgluconate-based pipette solution, thalamocortical synaptic currents were recorded while varying the holding potential in the voltage-clamp mode. 
Voltage or current records were low-pass filtered at $2-5 \mathrm{kHz}$, digitized at $10-20 \mathrm{kHz}$, saved to disk, and analyzed off-line. Data acquisition and processing was done with software written by A. Agmon in LabView (National Instruments, Austin, TX). All membrane potential values were corrected for a junction potential of $-11 \mathrm{mV}$ (Agmon et al., 1996).

Data analysis. The action potentials elicited by current steps were analyzed with MiniAnalysis (Synaptosoft, Leonia, NJ) to determine the threshold for action potential initiation and the amplitude of the afterhyperpolarizing potential (AHP). The action potential threshold was determined as the point at which the second derivative of the voltage trace was zero. The AHP amplitude was defined as the minimum point relative to threshold after the decay phase of the action potential. The spike frequency adaptation ratio was defined as the ratio of the first interspike interval divided by the average of the last three interspike intervals during a 500- to $800-\mathrm{msec}-1$ ong spike train. Input resistance was calculated from the voltage response induced by a $500-800 \mathrm{msec}$ hyperpolarizing current pulse.

Morphological identification. For morphological characterization of individual neurons, $1-2 \mathrm{mg} / \mathrm{ml}$ biocytin (Sigma, St. Louis, MO) was included in the intracellular solutions. After fixing overnight with $4 \%$ paraformaldehyde, rinsing with PBS, and permeabilizing with $0.25 \%$ Triton X-100, the slices were incubated for $3 \mathrm{hr}$ with $\mathrm{ABC}$ solution (Vector Laboratories, Burlingame, CA). After five rinses in PBS, the slices were preincubated with $0.7 \mathrm{mg} / \mathrm{ml}$ of $3^{\prime} 3^{\prime}$-diaminobenzidine (DAB; Sigma) for $15 \mathrm{~min}$, and then the reaction was initiated by adding $0.3 \% \mathrm{H}_{2} \mathrm{O}_{2}$. The reaction was stopped by rinsing with ice-cold PBS, and the slices were mounted in PBS-glycerol, coverslipped, and sealed with nail polish. Stained neurons were visualized on an Olympus AX microscope with a $60 \times$, NA 1.2 , long working-distance water-immersion objective or a $100 \times$, NA 1.4, oil immersion objective, traced and digitally reconstructed with Neurolucida (MicroBrightField, Colchester, VT). Digital images were taken using a Magnafire CCD camera (Optronics, Goleta, CA).

Identification of interneurons expressing parvalbumin and calbindin- $28 \mathrm{~K}$. After fixing overnight with $4 \%$ paraformaldehyde, the slices were washed three times with Tris buffer and incubated for $1 \mathrm{hr}$ in $0.25 \%$ Triton X-100 in Tris buffer and 5\% normal horse serum (NHS). Slices were then incubated for $3 \mathrm{~d}$ at $4{ }^{\circ} \mathrm{C}$ with a 1:500 dilution of mouse anti-parvalbumin (PV) monoclonal antibody (P-3171; Sigma) and/or a 1:500 dilution of rabbit anti-calbindin-28K (CB) polyclonal antibody (AB1778; Chemicon, Temecula, CA) in $0.25 \%$ Triton X-100 in Tris buffer with $1 \%$ NHS. Next, slices were washed three times with Tris buffer and incubated $3 \mathrm{~d}$ in a 1:500 dilution of allophycocyanin-conjugated goat anti-mouse IgG antibody (Molecular Probes, Eugene, OR) to label the PV-expressing cells, and in a 1:1000 dilution of Alexa 546-conjugated goat anti-rabbit IgG (Molecular Probes) to label the CB-expressing cells, in $0.25 \%$ Triton $\mathrm{X}-100$ in Tris buffer with $1 \%$ NHS. Slices were then washed with Tris buffer, mounted in PBS-glycerol, coverslipped, and sealed with nail polish. Images of the fluorescently labeled cells were obtained using a Zeiss LSM510 confocal microscope. The PV- and CB-expressing cells were visualized with the $633 \mathrm{~nm}$ red $\mathrm{HeNe}$ laser excitation line $(650 \mathrm{~nm}$ emission filter) and with the $543 \mathrm{~nm}$ green $\mathrm{HeNe}$ laser excitation line (560-615 nm emission filter), respectively. To identify the recorded neurons on the confocal microscope, Lucifer yellow (potassium salt, 1 $\mathrm{mg} / \mathrm{ml}$; Sigma) was included in the patch pipette in addition to biocytin, and the Lucifer yellow fluorescence was visualized using the $488 \mathrm{~nm}$ line of the Argon laser. Alternatively, slices were incubated with a $1 \mu \mathrm{g} / \mathrm{ml}$ solution of fluorescein isothiocyanate-conjugated streptavidin (Molecular Probes) for 30 min after completing the incubation with the secondary antibody and then visualized with the $488 \mathrm{~nm}$ laser line $(530-585 \mathrm{~nm}$ emission filter). After immunocytochemical characterization, a DAB reaction was performed as described above (under "Morphological identification"), starting with the five rinses with PBS.

Statistical tests. To determine statistical significance of difference between means, the observed difference was compared to differences calculated from 10,000 random permutations of the labels (Good, 1999). Permutation tests were programmed in Mathcad (Mathsoft, Cambridge, MA).

\section{RESULTS}

\section{Distinguishing inhibitory from excitatory neurons}

To characterize the neocortical interneurons that mediate feedforward inhibition, neurons in layers IV and $\mathrm{V}$ of the mouse somatosensory (barrel) cortex were tested in the cell-attached configuration, which does not disrupt the ionic and electrical integrity of the neurons, for action potential firing in response to thalamocortical stimulation. Their intrinsic firing patterns and thalamocortical synaptic responses were subsequently recorded in the whole-cell configuration. Recordings were made from a total of 135 neurons sampled from 67 slices prepared from 48 juvenile mice, 9- to 18-d-old. The basic experimental setup is shown in Figure 1. Inclusion of biocytin in the pipette allowed the recorded neurons to be morphologically identified post hoc as either inhibitory or excitatory neurons: excitatory cortical neurons have either pyramidal or spiny stellate morphologies, whereas inhibitory interneurons exhibit nonpyramidal, aspiny, or sparsely spiny morphologies (Simons and Woolsey, 1984; Peters and Kara, 1985a,b). Because not all of our neurons were recovered morphologically, the intrinsic firing patterns of the recorded cells were also used to distinguish inhibitory from excitatory neurons. As previously described (McCormick et al., 1985), pyramidal neurons encountered in this study showed strongly adapting responses to depolarizing current pulses. Typically, the first two or three spikes in a train occurred at much shorter interspike intervals than the rest of the spike train (data not shown). The firing patterns of the neurons that we identified morphologically as spiny stellate cells were also examined. As shown in Figure $2 A$, left, spiny stellate cells were multipolar, with several fine dendrites radiating out from the soma. When observed at high magnification, their dendrites exhibited numerous spines (short arrows). Injection of depolarizing current pulses (Fig. $2 A$, right) induced the firing of action potentials that, as in pyramidal neurons, showed strong frequency adaptation. In addition, the AHP at the end of each action potential (arrowhead) was small and repolarized slowly. In contrast, neurons identified morphologically as inhibitory interneurons, i.e., neurons that were neither pyramidal nor spiny stellates in morphology (Fig. 2B, left), exhibited much less spike frequency adaptation during induced trains of action potentials (Fig. 2B, right) and AHPs that were generally larger and repolarized faster (arrowhead). These differences are quantified and plotted in Figure $2 C$, in which only neurons with a positive morphological identification are included. Because there was virtually no overlap between spike train parameters of morphologically identified excitatory and inhibitory neurons, the intrinsic firing patterns were used to distinguish inhibitory from excitatory neurons in those cases in which morphological identification was not possible. In total, our sample of whole-cell recordings included 19 pyramidal neurons, 11 spiny stellate cells, and 105 inhibitory interneurons.

\section{Spikes in inhibitory interneurons are appropriately timed to mediate disynaptic inhibition}

To mediate feedforward, disynaptic inhibition, interneurons should fire at a monosynaptic latency after a thalamocortical volley, and their action potentials should evoke inhibitory responses in surrounding neurons. As shown in Figure 3, inhibitory interneurons indeed discharged in a manner consistent with this expectation. The left vertical guideline in this figure indicates the onset of the thalamocortically evoked field potential (Fig. 3A), which is a good indicator for the onset of the monosynaptic excitatory postsynaptic response in the layer IV population (Agmon and Connors, 1991, 1992). A spiny stellate neuron in the barrel did not discharge spikes in the cell-attached (CA) mode of recording (Fig. 3B, top trace), but when recorded in the whole-cell voltage-clamp (WC) mode (Fig. 3B, middle and bottom traces), it was found to receive an EPSC coincident with the monosynaptic field potential (left guideline). This monosynaptic EPSC was immediately followed by an IPSC, the onset of which is indicated by 


\section{A Spiny Stellate Cell}

Figure 2. Morphologically identified excitatory and inhibitory neurons exhibit distinct firing patterns. $A, B$, Images of representative neurons labeled with biocytin and their corresponding voltage responses to hyperpolarizing and depolarizing current steps (arrows). A, A spiny stellate cell. Note the extremely thin and spine-bearing dendrites and the profoundly adapting spikes with shallow rounded AHPs (arrowhead). B, An inhibitory interneuron. Note the relatively thick, aspiny dendrites and that the action potentials exhibit less adaptation and deeper, shorter AHPs (arrowhead). Scale bar: $A, 30 \mu \mathrm{m} ; B, 50 \mu \mathrm{m}$. Pial surface is up. $C$, Separation of morphologically identified inhibitory interneurons $(n=56)$, pyramidal cells $(n=5)$, and spiny stellate cells $(n=7)$ according to their AHP peak amplitudes and spike frequency adaptation ratios (see Materials and Methods). Note that with one exception in each case, all neurons with an AHP amplitude $>10 \mathrm{mV}$ were morphologically identified as inhibitory interneurons, whereas all neurons with AHP amplitude $<10 \mathrm{mV}$ were morphologically identified as excitatory (pyramidal or spiny stellate). There was also very little overlap in adaptation ratios.
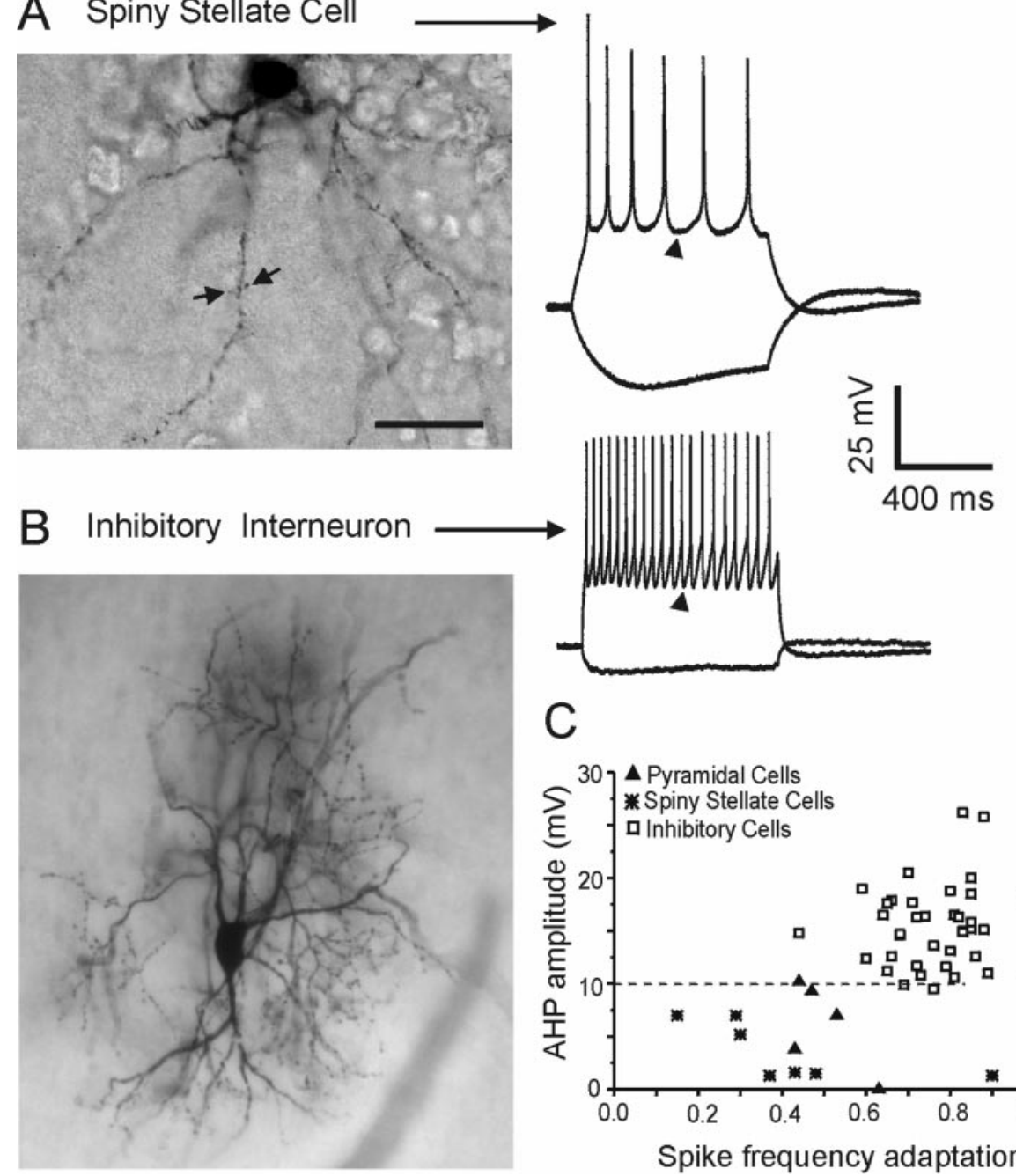

the right vertical guideline. The inhibitory nature of this second response is evident from the record at a depolarized potential, which shows that at $-35 \mathrm{mV}$ the current was already outward, indicating an inhibitory reversal potential. The IPSC began 3.0 msec after the onset of the EPSC, a latency that leaves time for one intercalated inhibitory neuron to fire.

The inhibitory interneuron recorded in the same barrel (Fig. $3 D$, bottom cell) could have been such an intercalated neuron. Examination of this neuron in the whole-cell voltage-clamp mode (Fig. 3C, middle and bottom traces) indicated that it received a thalamocortical input nearly coincident with the monosynaptic field potential. This coincidence, and the negligible sweep-tosweep variability in the onset of the whole-cell responses (note superimposed traces), indicate that these were monosynaptic EPSCs (Agmon and Connors, 1992; Agmon et al., 1996). This neuron discharged a single spike (Fig. 3C, top trace) with an average latency of $1.8 \mathrm{msec}$ after the onset of the monosynaptic EPSC (left guideline) and $1.2 \mathrm{msec}$ before the onset of the disynaptic IPSC in the spiny stellate cell (right guideline). Analysis of the latencies from the onset of the postsynaptic component of the field potential to all the monosynaptic EPSCs and spikes in 59 inhibitory interneurons, and to the IPSCs in 17 excitatory neurons (Fig. $3 E$ ), indicated that, as a population, the spikes followed the monosynaptic EPSCs in the inhibitory interneurons by 1.9 msec and preceded the IPSCs in the excitatory neurons by 1.3 msec (median-to-median intervals), as expected if these spikes were mediating disynaptic inhibition.

\section{Inhibitory interneurons receive feedforward inhibition}

Similar to the inhibitory interneuron shown in Figure 3, all but three of the 59 inhibitory interneurons that discharged spikes in response to thalamocortical stimulation fired single action potentials. This was somewhat surprising, because inhibitory cortical neurons are capable of firing trains of action potentials at high frequency when activated by synaptic inputs in vitro (McCormick et al., 1985; Agmon and Connors, 1992) or in vivo (Swadlow, 1989; Azouz et al., 1997; Zhu and Connors, 1999). We hypothesized that the inhibitory interneurons in our sample were prevented from firing multiple spikes by short-latency disynaptic inhibition mediated by other inhibitory interneurons in their barrel column. Examination of synaptic responses of the inhibitory interneuron shown in Figure 3 at a holding potential of $-31 \mathrm{mV}$ indicated that this cell, like the spiny stellate in the same column, received disynaptic inhibition (Fig. $3 C$; this cell appeared to receive a dual IPSC: the onset of the first IPSC is indicated by an arrow, whereas the onset of the second IPSC coincided with the IPSC in the spiny stellate cell and is indicated by the right vertical guideline). Of the 15 inhibitory interneurons that fired single spikes in response to thalamic stimulation and were tested for inhibitory inputs, 11 received disynaptic IPSCs at a latency consistent with the hy- 


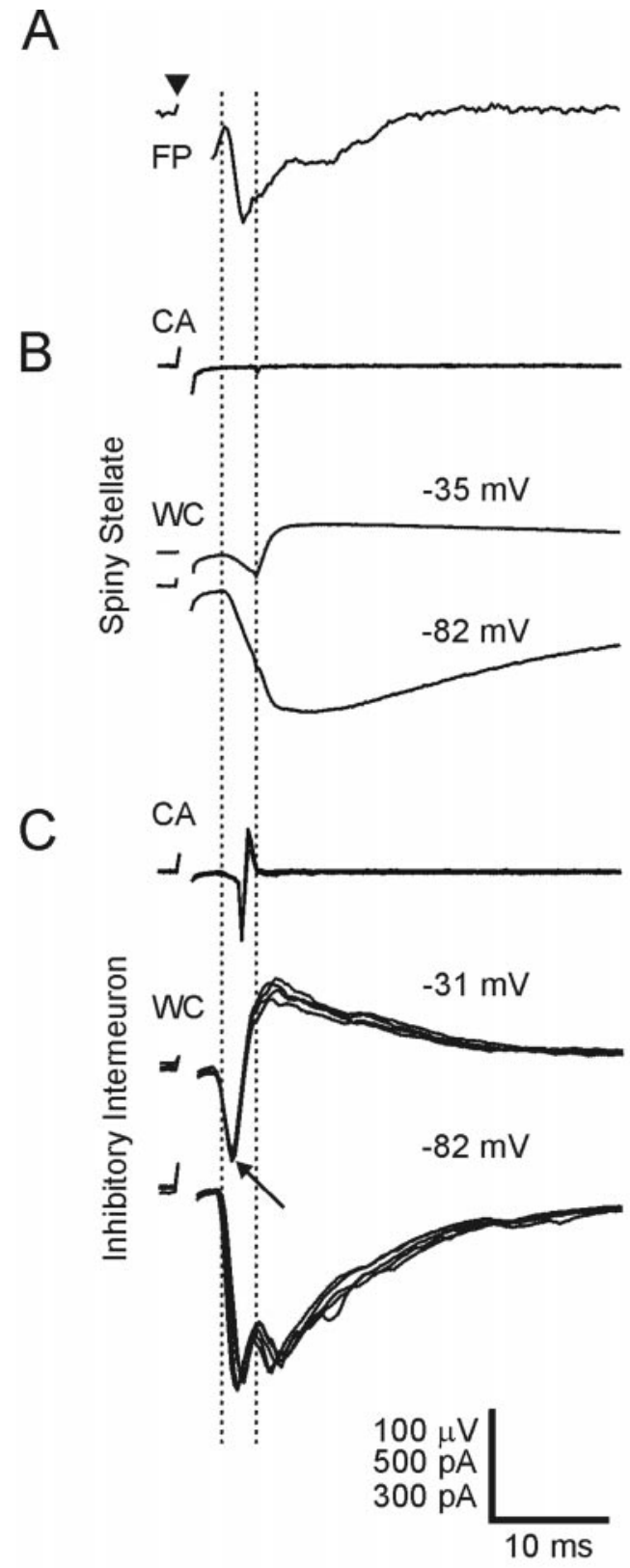

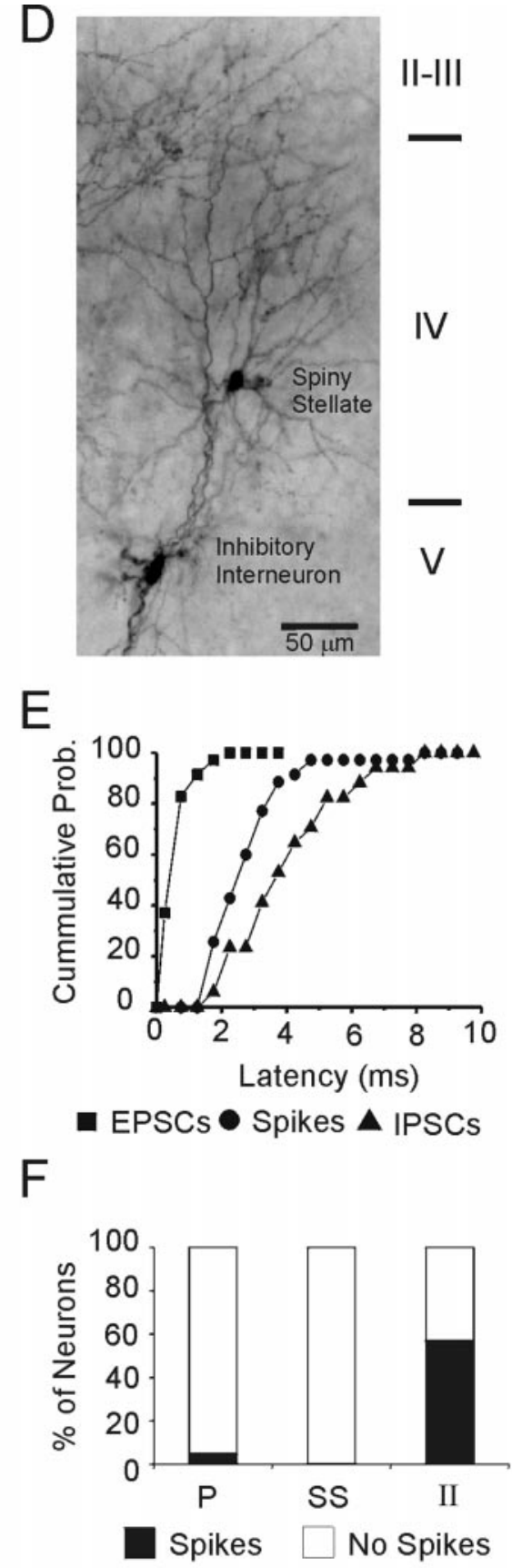

Figure 3. Interneuronal spikes are appropriately timed to mediate disynaptic inhibition. All traces were recorded from the same barrel column and are aligned on the stimulus onset. $A$, Averaged thalamocortically evoked field potential $(F P)$ recorded in layer IV. The arrowhead indicates the stimulus onset; the left vertical guideline indicates the onset of the field EPSP. B, A spiny stellate cell. Top panel, Four superimposed cell-attached responses $(C A)$ with no detectable spikes; bottom panels, averaged whole-cell responses $(W C)$ with holding potentials indicated above each trace. This cell received a monosynaptic EPSC (onset coincident with field EPSP, left guideline; note that the postsynaptic current is inward at both holding potentials) followed by a disynaptic IPSC (onset indicated by the right guideline; note that the postsynaptic current reverses between -82 and $-35 \mathrm{mV}) . C$, An inhibitory interneuron. Top panel, Four superimposed cell-attached responses; note that the cell fired consistently. Bottom panels, Four or five superimposed whole-cell responses. This cell received a monosynaptic EPSC slightly before the EPSC in the spiny stellate cell (left guideline), followed by a dual IPSC, the early IPSC indicated by the arrow, and the late IPSC coincident with the IPSC in the spiny stellate cell (right guideline). Vertical calibrations apply, from top to bottom, to $A, B$, and $C$, respectively. $D$, Biocytin staining of the two neurons illustrating their relative locations in the same barrel column. $E$, Cumulative probabilities of the latencies of EPSCs and spikes in 59 barrel interneurons and of IPSCs in 17 excitatory neurons, in response to thalamocortical stimulation. Latencies were measured from the beginning of the field EPSP. $F$, The fraction of pyramidal $(P$; $n=19)$, spiny stellate $(S S ; n=11)$, and inhibitory (II; $n=105$ ) neurons that fired (filled bars) or did not fire (open bars) in response to thalamic stimulation. pothesis that disynaptic inhibition prevented them from firing multiple action potentials.

Although most interneurons fired only once, three interneurons fired trains of long-latency action potentials after thalamocortical activation. Whole-cell recordings showed that these trains coincided with long-latency barrages of synaptic inputs (data not shown), similar to those reported in mouse somatosensory cortex during the first postnatal week (Agmon et al., 1996). Interneurons firing long-latency barrages were excluded from further analysis.

\section{Excitatory neurons were less responsive to thalamic inputs}

Of 105 inhibitory interneurons recorded from in the cell-attached mode, $57 \%$ fired action potentials at an apparent monosynaptic latency (Fig. $3 F$, right bar). In marked contrast to the responsiveness of interneurons, the majority of excitatory neurons examined in this study did not discharge in response to thalamic stimulation. A population of 30 excitatory cells in layers IV-V, 19 pyramidal cells and 11 spiny stellate cells, were examined for spike discharges in response to the same range of intensities of thalamic stimulation used to evoke spikes in the inhibitory interneurons. Only a single pyramidal neuron fired (Fig. $3 F$ ), although $75 \%$ of all excitatory cells tested in the whole-cell mode $(n=20)$ were found to receive thalamocortical EPSCs (Fig. 3B). These results indicate that inhibitory interneurons are considerably more excited by thalamic input than excitatory neurons.

\section{Selective activation of some inhibitory interneurons}

As summarized in Figure $3 F$, close to half of the inhibitory interneurons in our sample did not fire in response to thalamocortical stimulation. Because our study was conducted in a slice preparation, many thalamocortical axons were likely to have been 
A

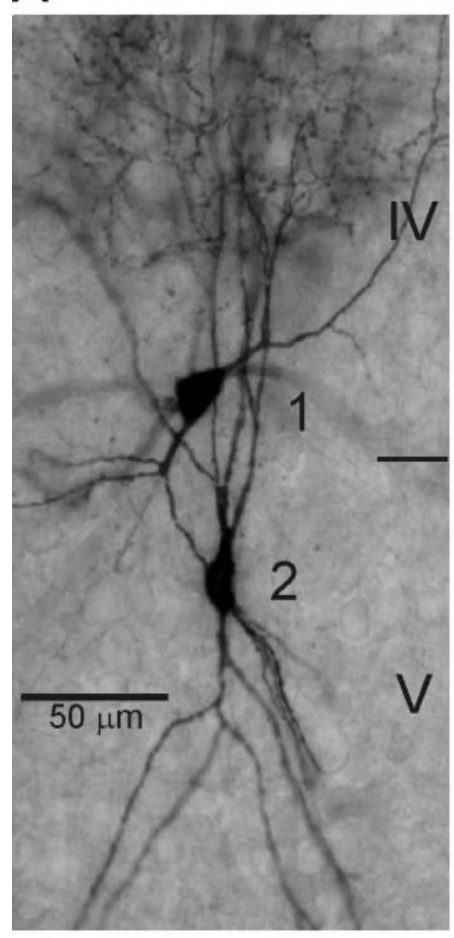

B
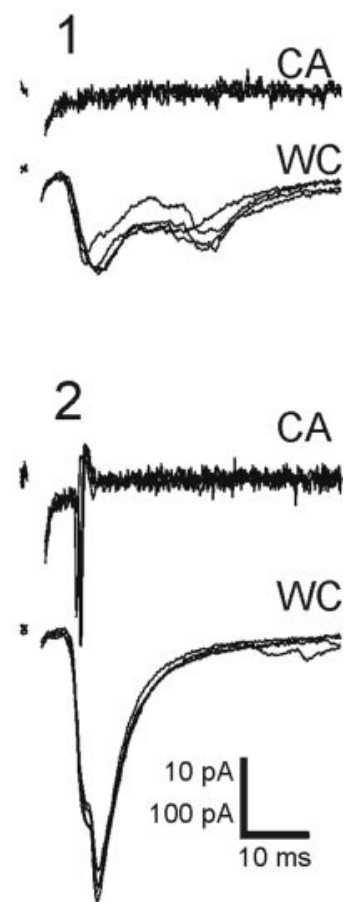

Figure 4. Thalamocortical stimulation activates some interneurons but not others. $A$, Two biocytin-filled inhibitory interneurons in the same barrel. $B$, Four superimposed traces $(5 \mathrm{sec}$ intervals) from interneuron 1 (top traces) and interneuron 2 (bottom traces) in the cell-attached $(C A)$ and whole-cell $(W C)$ modes. Note that despite the close proximity between the two cells, thalamic stimulation elicited spikes only in interneuron 2 . Cell 1 was stimulated at $100 \mu \mathrm{A}$, and cell 2 was stimulated at $40 \mu \mathrm{A}$. Calibration is $10 \mathrm{pA}$ for CA and $100 \mathrm{pA}$ for WC.

truncated during the slicing procedure. In addition, the density of intact thalamocortical innervation in the thalamocortical slice varies between barrels (Agmon et al., 1993). Therefore, it was possible that inhibitory interneurons that did not fire were located in barrels that did not receive thalamocortical inputs. That this was not the case was evident from the records of 24 nondischarging inhibitory interneurons tested for thalamocortical synaptic inputs in the whole-cell mode. Of these, 79\% were found to receive monosynaptic thalamocortical inputs. Moreover, often other inhibitory interneurons in the very same barrel column did fire in the cell-attached mode, making it unlikely that the absence of firing was attributable to a loss of intact thalamocortical axons. An example is shown in Figure 4, which illustrates two inhibitory interneurons in close proximity within a single barrel (Fig. 4A). Only interneuron 2 fired in the cell-attached mode in response to thalamocortical activation (Fig. $4 B, C A$ ), but both cells exhibited a monosynaptic EPSC in the whole-cell mode (Fig. $4 B, W C$ ). Of the 45 inhibitory interneurons that did not fire in response to thalamocortical stimulation, $58 \%$ were located in barrels or columns in which at least one other interneuron did fire. Thus, in the in vitro thalamocortical slice some inhibitory interneurons discharge in response to a thalamocortical input volley, but others do not.

\section{Amplitude of synaptic input determines responsiveness to thalamic stimulation}

Whether a neuron fires in response to a synaptic input or not is determined by two general factors, the strength of the input and

the intrinsic integrative properties of the neuron. For example, all intrinsic parameters being equal, a stronger synaptic input would be more effective in firing the cell than a weaker one, whereas for a given strength, a synaptic input would be more effective if the neuron had a higher input resistance or a lower firing threshold relative to the resting membrane potential. To determine whether the discharging interneurons exhibited intrinsic properties that made them more responsive to thalamic inputs, the input resistance, resting membrane potential, and the threshold for action potentials were compared between discharging and nondischarging inhibitory interneurons and between discharging inhibitory interneurons and nondischarging excitatory neurons. There were no statistically significant differences in resting membrane potential between discharging inhibitory interneurons and either inhibitory or excitatory nondischarging neurons (Table $1 ; \mathrm{V}_{\mathrm{m}}$, twotailed probabilities were $p=0.19$ and $p=0.59$, respectively). The amount of depolarization required to reach threshold (Table 1; Threshold- $\mathrm{V}_{\mathrm{m}}$ ) was, on average, somewhat higher in the discharging inhibitory interneurons compared to nondischarging inhibitory or excitatory neurons ( $p=0.06, p=0.03$, respectively), and the discharging interneurons had a significantly lower input resistance than either inhibitory or excitatory nondischarging cells (Table $1 ; \mathrm{R}_{\mathrm{m}}, p<0.01$ and $p<0.0001$, respectively). Both of these differences, however, would actually make the discharging interneurons less sensitive to synaptic input and therefore cannot account for the observed differences in response to thalamocortical stimulation. This suggested that interneurons that discharged received larger thalamocortical synaptic inputs, as in the case shown in Figure $4 B$. Consistent with this hypothesis, thalamocortical stimulation induced, on average, fivefold larger synaptic currents in the interneurons that discharged spikes compared to inhibitory neurons that did not fire and to excitatory neurons (Table $1 ; I_{\text {synaptic }}, p<0.0001$ ).

\section{Both fast spiking and regular-spiking nonpyramidal interneurons mediate feedforward inhibition}

Inhibitory cortical interneurons exhibit different patterns of repetitive firing in response to intracellular current injections (Kawaguchi and Kubota, 1997). This diversity suggests that different types of interneurons express different palettes of voltageand calcium-gated channels and are likely to respond differently during natural, thalamocortically relayed sensory stimulation. It was therefore of interest to determine the firing patterns in our sample of thalamocortically discharging inhibitory interneurons. Figure $5 A$ shows repetitive firing elicited in the two interneurons illustrated in Figure 4 (cell 1 and cell 2, left and middle traces, respectively) and in a third cell that discharged in response to thalamic stimulation (right trace). It is evident that the three interneurons exhibited markedly different spike frequency adaptation patterns, with the left trace showing the most adaptation, and the right trace the least adaptation. To characterize such differences quantitatively, we recorded spike trains from 57 discharging and nondischarging inhibitory interneurons and calculated a spike frequency adaptation ratio from each record (see Materials and Methods; adaptation ratios are indicated in Fig. $5 \mathrm{~A}$ above each trace). The histogram of the spike frequency adaptation ratios exhibited two large peaks (Fig. 5B). A value of 0.8 , which lies between the two major peaks, was used to divide the population into two groups, one with adaptation ratios $\geq 0.8$, and one with adaptation ratios $<0.8$, which were called, following the nomenclature of Kawaguchi (1995), fast spiking (FS) and regularspiking nonpyramidal (RSNP) cells, respectively. For example, 
Table 1. Intrinsic and synaptic properties of discharging and nondischarging inhibitory and excitatory neurons

\begin{tabular}{|c|c|c|c|c|}
\hline & $\mathrm{V}_{\mathrm{m}}(\mathrm{mV})$ & Threshold- $\mathrm{V}_{\mathrm{m}}(\mathrm{mV})$ & $\mathrm{R}_{\mathrm{m}}(\mathrm{M} \Omega)$ & $\mathrm{I}_{\text {synaptic }}(\mathrm{pA})$ \\
\hline Discharging interneurons & $-67 \pm 1.0(39)$ & $27.0 \pm 1.1(39)$ & $243 \pm 24(26)$ & $359 \pm 43(33)$ \\
\hline Nondischarging interneurons & $-69.3 \pm 1.3(18)$ & $23.1 \pm 1.8(18)$ & $414 \pm 64(14)^{*}$ & $72 \pm 17(15)^{* *}$ \\
\hline Excitatory neurons & $-66 \pm 2.0(19)$ & $22.0 \pm 2.4(17)^{*}$ & $553 \pm 56(19)^{* *}$ & $70 \pm 13(15)^{* *}$ \\
\hline
\end{tabular}

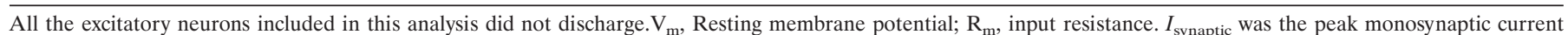

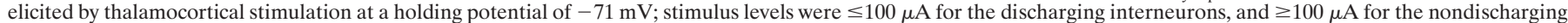

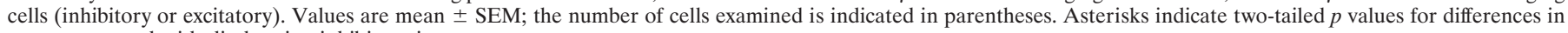
mean compared with discharging inhibitory interneurons. ${ }^{*} p<0.05 ; *{ }^{*} p<0.0001$.

A

A $\quad A R=0.44$

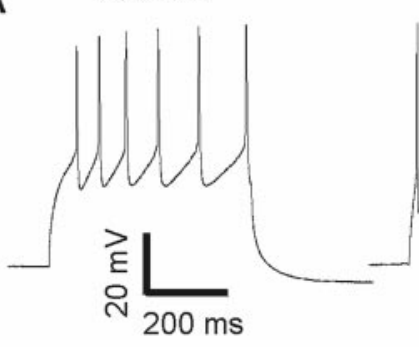

$\mathrm{AR}=0.71$
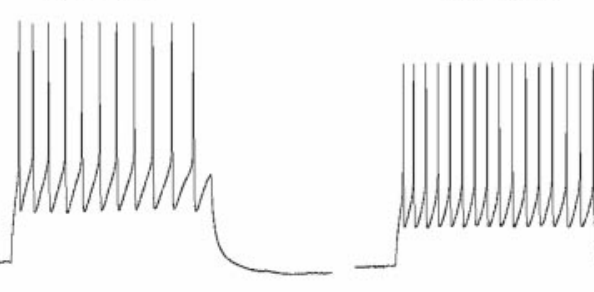

$A R=0.99$

B

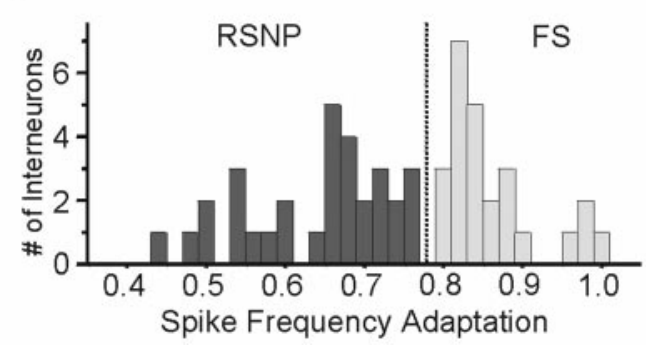

C

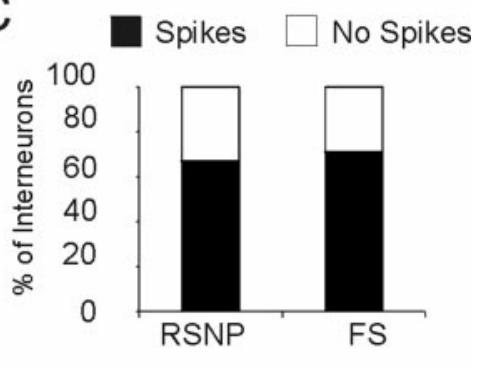

Figure 5. Both adapting (RSNP) and nonadapting $(F S)$ interneurons mediate thalamocortical feedforward inhibition. $A$, Intrinsic firing patterns of three inhibitory interneurons that fired in response to thalamic stimulation, illustrating the large differences in spike frequency adaptation during the $500 \mathrm{msec}$ current pulse. The left and middle traces are, respectively, from cells 1 and 2 in Figure 4. $B$, The distribution of spike frequency adaptation ratios in a sample of 56 inhibitory interneurons. The value of 0.8 was selected as a separation point between the FS and RSNP cell classes. $C$, Probability of thalamocortically evoked firing of 24 FS and 33 RSNP neurons. Differences were statistically insignificant. the two neurons whose spike trains are illustrated in the left and middle traces of Figure $5 \mathrm{~A}$ were classified as RSNP, whereas the neuron represented by the rightmost spike train was classified as FS. Unlike adapting inhibitory interneurons in layer $\mathrm{V}$ of rat frontal cortex (Kawaguchi, 1993; Xiang et al., 1998), RSNP neurons in our sample did not exhibit a low-threshold spike (LTS) after recovery from hyperpolarization.

Of all 57 inhibitory interneurons in our sample tested for firing patterns, 58\% were classified as RSNP and $42 \%$ as FS. Of 39 thalamocortically discharging inhibitory interneurons, $56 \%$ were classified as RSNP and $44 \%$ as FS. As shown in Figure 5C, probabilities of firing in response to thalamocortical stimulation were $66 \%$ for RSNP interneurons and $71 \%$ for FS cells, and the difference was statistically insignificant ( $p=0.48$; Fisher's exact test, single-tailed). We conclude that inhibitory interneurons from both classes contribute to feedforward inhibition, approximately at the ratio of their occurrence in the general population.

\section{Interneurons expressing PV or CB are excited by thalamic input}

Cortical inhibitory interneurons can be characterized by their pattern of expression of calcium-binding proteins such as PV and CB (Celio, 1986; Hendry et al., 1989; Kawaguchi and Kubota, 1993; Cauli et al., 1997). The calcium-binding protein content of an inhibitory interneuron correlates with its level of metabolic activity (Maier and McCasland, 1997) and is also an indicator of the neuropeptides that it co-releases with GABA (Cauli et al.,
1997). It was therefore of interest to determine the calciumbinding protein content in the population of thalamocortically discharging inhibitory interneurons. Figure $6 A$ illustrates a neuron that discharged spikes in response to thalamic stimulation and was found to express PV. Of 30 discharging interneurons tested, $50 \%$ were found to express PV. Thirteen neurons of the same group were tested also for CB immunoreactivity; $15 \%$ were CB positive, and one neuron expressed both markers. We conclude that both PV-expressing and CB-expressing interneurons contribute to feedforward inhibition in the barrel cortex, as do interneurons expressing neither marker.

To test whether thalamocortical inputs excite preferentially PV- and/or CB-expressing inhibitory interneurons, we also tested nondischarging neurons for $\mathrm{PV}$ and $\mathrm{CB}$ immunoreactivity. A total of 42 discharging and nondischarging inhibitory interneurons were tested for PV immunoreactivity (including the cells described above), and $43 \%$ were immunopositive. Of these, $83 \%$ responded to thalamic input with spikes, whereas of the interneurons that were immunonegative for PV, only $63 \%$ fired (Fig. 6B). Thus, PV-expressing neurons tended to have a higher probability of firing compared with PV-immunonegative cells; however this difference did not attain statistical significance $(p=0.13$; Fisher's exact test, single-tailed). Of 20 inhibitory interneurons tested for $\mathrm{CB}$ immunoreactivity, three were found to express calbindin, and all three fired, whereas of the $17 \mathrm{CB}$-immunonegative interneurons, 59\% fired (Fig. 6C). The difference in firing probability 


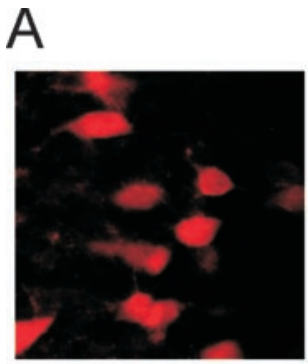

Parvalbumin

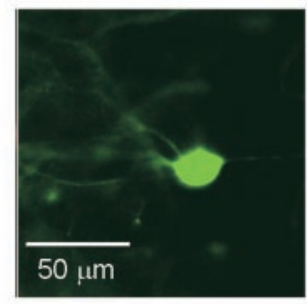

Lucifer Yellow

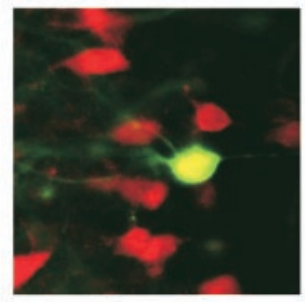

Overlay

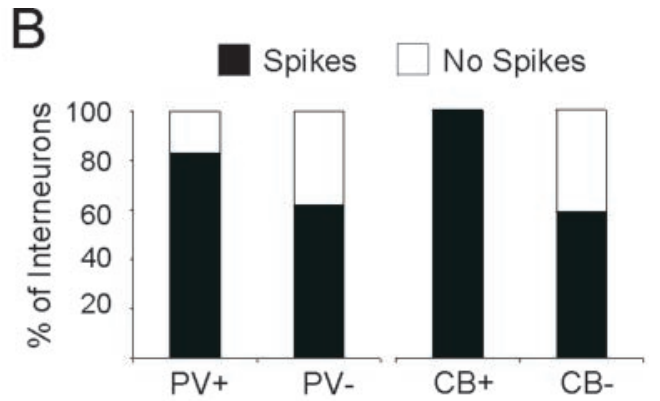

Figure 6. PV- or CB-immunopositive and immunonegative interneurons mediate feedforward thalamocortical inhibition. $A$, Confocal images of layer IV in a thalamocortical slice stained for PV. Pia is toward the left. Left, PV immunofluorescence (red). Center, the same microscopic field showing Lucifer yellow fluorescence (green) in a recorded interneuron that discharged in response to thalamic stimulation. Right, Overlay of the two panels at left, showing colocalization (yellow) of Lucifer yellow and PV. B, Thalamocortically evoked firing probability in a population of PV-immunopositive (PV+; $n=18)$, PV-immunonegative (PV-; $n=24)$, CB-immunopositive (CB+; $n=3$ ), and CB-immunonegative (CB-; $n=17)$ inhibitory interneurons. Differences were not statistically significant.

between CB-immunopositive and -immunonegative cells was not statistically significant ( $p=0.25)$. There was also no correlation in our sample between calcium-binding protein expression and firing patterns $(p=0.26)$. We conclude that the type of calciumbinding protein expressed by an inhibitory interneuron is only weakly correlated with its probability of activation by thalamocortical afferents.

\section{Several distinct morphological types of interneurons mediate disynaptic thalamocortical inhibition}

Neocortical inhibitory interneurons are a highly diverse group, not only in their firing patterns and calcium-binding protein contents, but also in their morphologies (Houser et al., 1983; Cobas et al., 1987; Kisvarday et al., 1990; Lorente de Nó, 1992; Prieto et al., 1994; Kawaguchi and Kubota, 1997). Of all morphological features, probably the one most likely to affect the functional role of a neuron in the cortical circuit is the spatial distribution of its synaptic terminals, which can be inferred from the distribution of its axonal arborizations. It was therefore of interest to determine the axonal trajectories of thalamocortically discharging inhibitory interneurons in our sample. A total of 19 biocytin-stained discharging interneurons, selected for good filling of their axonal arbors, were reconstructed morphologically; of these, 11 are illustrated in Figure 7. With two exceptions, all the reconstructed interneurons had cell bodies within layer IV or straddling the IV/V border and had most of their dendritic processes (Fig. 7, blue) within layer IV. Based on their axonal arbor (Fig. 7, red), the reconstructed neurons fell into five morphological types $(A-E)$. Types $\mathrm{A}$ and $\mathrm{B}$ had an axonal arbor that formed a dense plexus coextensive with their dendritic tree, either restricted to layer IV (type A; $n=5$ ) or extending into lower layer III (type B; $n=4$ ), with only sparse branches in layer $\mathrm{V}$, if at all. Type $\mathrm{C}$ was represented in our sample by two neurons with a cell body in lower layer $\mathrm{V}$ and with dendrites straddling the layers V/VI border and not extending into layer IV. Both had an elaborate axonal plexus in layer IV, and one (Fig. 7C) had a bilaminar axonal plexus, with a lower plexus in lower layer $\mathrm{V}$ surrounding its dendritic tree. Types D and E had axonal trees that formed a plexus extending beyond the dendritic branches into layers II/III vertically (type $\mathrm{D} ; n=2$ ) or both vertically and horizontally (type $\mathrm{E} ; n=6$ ). The horizontal extent in layers II/III of the axonal arbor of type E varied between 350 and 776 $\mu \mathrm{m}$. Because our plane of section was approximately parallel to the rows of barrels (A. Agmon, unpublished observations) and therefore parallel to the minor axis of the barrels, which in mouse is $<200-\mu \mathrm{m}$-long (Woolsey and Van der Loos, 1970), excitation of type E interneurons would provide inhibition to at least one additional barrel column in the same row, on either or both sides of their own column. Several neurons of all five types, specifically those with cell bodies close to the layers IV/V border, closely resembled the so-called "Lorente de Nó cells" (Cobas et al., 1987; Fairén, 1993) (compare the middle neuron of Fig. $7 B$ to Fig. 13C of Lorente de Nó, 1992). The morphological type of a neuron appeared to be independent of its immunocytochemical or electrophysiological identities; for example, both immunopositive and immunonegative $\mathrm{PV}$ and $\mathrm{CB}$ interneurons and both $\mathrm{FS}$ and RSNP cells were among those classified as type A. We conclude that several distinct morphological types of interneurons mediate feedforward thalamocortical inhibition, some of them generating feedforward inhibition within their own barrels, whereas others are likely to relay disynaptic inhibition to the upper cortical layers within their own columns and to columns outside their barrel of origin.

\section{DISCUSSION}

Disynaptic, feedforward inhibition plays an all-important role in the initial processing of incoming sensory information by the neocortex, but the precise identity of the interneurons that generate it has been largely unknown. To our knowledge this is the first detailed intracellular examination, in any cortical area, of inhibitory interneurons that fire in response to a thalamocortical input volley. Our results suggest that no single, uniform class of interneurons can be considered the sole source of disynaptic inhibition.

\section{Thalamic inputs preferentially excite inhibitory interneurons}

In the present study, excitatory neurons were unresponsive to the same intensities of thalamic stimulation that excited inhibitory interneurons. This finding is in agreement with previous data in vivo showing that, compared with excitatory neurons, putative inhibitory neurons respond more vigorously, at lower thresholds, and with shorter latencies (Simons, 1978; Yamamoto et al., 1988; Simons and Carvell, 1989; Swadlow, 1989; Welker et al., 1993) and are metabolically more active (Nie and Wong-Riley, 1995; McCasland and Hibbard, 1997). It was previously suggested (Simons, 1995) that the thalamocortical synapses may be more effective on inhibitory neurons because they impinge on their 


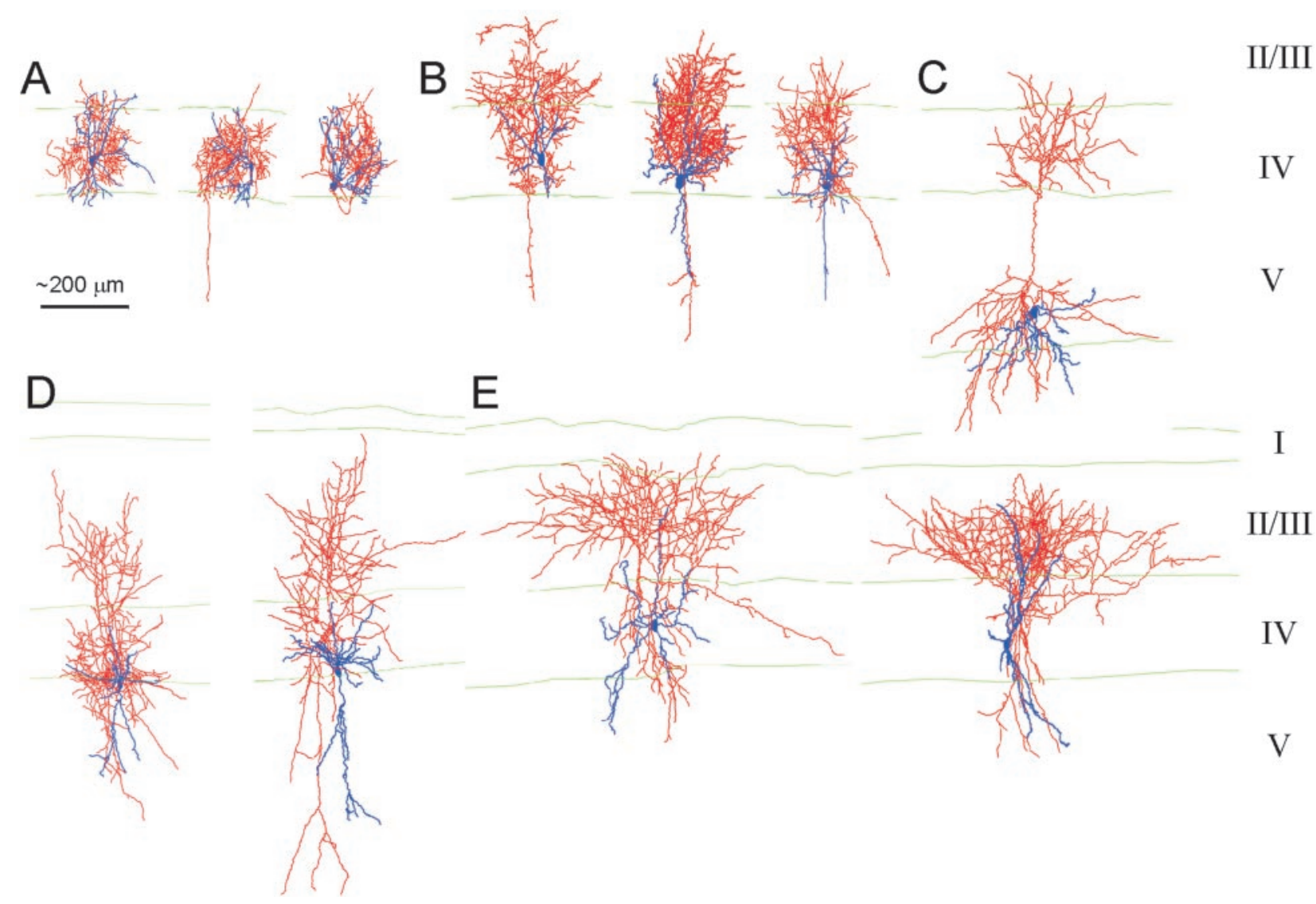

Figure 7. Several morphological types of interneurons mediate feedforward thalamocortical inhibition. Computer-assisted reconstructions of 14 biocytin-filled neurons, with cell bodies and dendritic trees in blue and axonal arborizations in red. Dendrites and axons are represented with lines of constant width. Laminar boundaries are indicated by thin green lines and labeled with roman numerals on the right. For ease of comparison, tracing sizes were adjusted to the same apparent vertical extent of layer IV, so the scale bar varies slightly between panels but is $\sim 200 \mu \mathrm{m}$. See Results for descriptions of the five morphological types.

somata and proximal dendritic shafts, while impinging on dendritic spines of excitatory neurons (Peters et al., 1976; White et al., 1984; Keller and White, 1987; Staiger et al., 1996). However, computational and analytical models suggest that the efficacy of excitatory inputs on spines and on dendritic shafts is likely to be similar (Johnston and Wu, 1995; Koch, 1999). Our data (Table 1) suggest that it is the considerably stronger thalamocortical synaptic currents in (some) inhibitory interneurons, compared with excitatory neurons, which accounted for the differences in firing probability. The effect of a larger synaptic current would be to generate a faster rising EPSP (because at the onset of the EPSP, $\mathrm{d} V_{\mathrm{m}} / \mathrm{dt}=-I_{\text {synaptic }} / C_{\mathrm{m}}$ ), causing the inhibitory interneurons to fire first and thereby to generate IPSPs in the excitatory neurons, preventing them from reaching threshold. A stronger thalamocortical synaptic current may be attributable to the higher single-channel conductance of AMPA-subtype glutamate receptors in inhibitory interneurons, most of which lack the GluR2 receptor subunit (Angulo et al., 1997; Swanson et al., 1997).

\section{Only a subset of all inhibitory interneurons are activated by thalamocortical inputs}

Our results indicate that only a subset of interneurons within each barrel column fired in response to thalamocortical stimulation. Comparison of responsive and nonresponsive inhibitory inter- neurons suggested that, as in the comparison with excitatory neurons above, it was not the intrinsic properties of the interneuron that determined its responsiveness, but most likely the magnitude of the thalamocortical synaptic input it received. The differences in the magnitude of thalamic input onto different inhibitory interneurons are probably the functional correlates of the variability in the numbers and locations of thalamocortical synapses made on them (White and Rock, 1981; White et al., 1984; Keller and White, 1987).

\section{Mutual suppression of firing by inhibitory interneurons}

The great majority of the inhibitory neurons examined in our study fired a single spike after thalamocortical stimulation. This could be explained by our finding that layer IV interneurons receive disynaptic thalamocortical inhibition, presumably via other inhibitory neurons in their vicinity. Dual recordings in the rat (Gibson et al., 1999) and cat (Tamas et al., 1998) have confirmed directly that neocortical layer IV interneurons inhibit other layer IV interneurons in their proximity. GABAergic cortical neurons can also inhibit themselves through autapses (Thomson et al., 1996; Tamas et al., 1997b). Thus, inhibitory interneurons effectively suppress each other's firing after their first spike, a mechanism that may allow for a faster recovery of the cortex from the inhibitory volley. 


\section{Both FS and RSNP interneurons mediate feedforward inhibition}

Inhibitory interneurons in our sample could be broadly divided by their intrinsic firing patterns into two groups, FS and RSNP, which differed in the degree of spike frequency adaptation. Similar differences in spike frequency adaptation were previously found among inhibitory interneurons in various cortical areas and layers (Kawaguchi, 1993; Hirsch, 1995; Kawaguchi, 1995; Cauli et al., 1997; Gibson et al., 1999; Dantzker and Callaway, 2000; Gupta et al., 2000). FS interneurons discharge at short latency in response to whisker stimulation in vivo (Simons, 1978; Swadlow, 1989; Zhu and Connors, 1999) and receive monosynaptic thalamocortical input in the thalamocortical slice (Agmon and Connors, 1992; Gibson et al., 1999). Our data confirm that FS interneurons are discharged by thalamocortical afferents, but show that RSNP interneurons, which are characterized by a pronounced spike frequency adaptation, also mediate feedforward inhibition. RSNP cells have not been identified in singleunit recordings, and therefore our data do not conflict with the extracellular studies cited above. Our findings are apparently at odds with those of Gibson et al. (1999), who report that thalamocortical responses are smaller and less frequently observed in the adapting (their LTS) compared with the nonadapting (FS) interneurons. Gibson et al. (1999) used a stimulation protocol that was intended to activate only a single axon; it is therefore possible that adapting interneurons receive convergent input from many thalamocortical axons, thereby compensating for the small size of each unitary EPSP. Alternatively, it is possible that there is no precise correspondence between the RSNP and LTS classes, or that differences in species or recording conditions (e.g., temperature) accounted for the discrepancy. Both nonadapting and adapting layer IV neurons are coupled to other neurons of their own kind by gap junctions (Galarreta and Hestrin, 1999; Gibson et al., 1999; Beierlein et al., 2000). Thus, thalamocortical activation of even a subset of these cells may result in a synchronous inhibitory spike volley caused by the spread of excitation through a large population of electrically coupled cells.

\section{Thalamic excitation of parvalbumin- and calbindin-expressing interneurons}

PV-expressing interneurons in the somatosensory cortex receive multiple thalamocortical contacts (Staiger et al., 1996) and are metabolically more active than CB-expressing interneurons (Maier and McCasland, 1997), suggesting that the former may be more likely to fire in response to thalamocortical input. In our sample we found a higher firing probability of PV-expressing compared to nonexpressing neurons, but this difference did not attain statistical significance. The fraction of PV-immunopositive cells in our sample (43\%) was smaller than found previously in layer IV (73\%; Ren et al., 1992), possibly because PV expression in layer IV has not peaked yet at the ages we studied (Sanchez et al., 1992; del Rio et al., 1994; Alcantara et al., 1996) or because of experimental limitations (e.g., dialysis of the antigen by the recording solution). This could have caused us to underestimate the difference in firing probabilities between PV-immunopositive and PV-immunonegative interneurons. Nevertheless, our data clearly show that neurons expressing $\mathrm{PV}$, neurons expressing $\mathrm{CB}$, and neurons expressing neither marker participate in feedforward inhibition.

\section{Morphological types of inhibitory interneurons and their functional roles}

Inhibitory interneurons of cortical layers IV and $\mathrm{V}$ activated thalamocortically were heterogeneous also in their dendritic and axonal morphologies. Within this heterogeneity, however, there was a clear grouping of cells into several distinct morphological types (Fig. 7), which differed in the vertical and horizontal distributions of their axons, and thereby in their potential role in the thalamocortical circuit. Thus, neurons of type A, with an axonal arbor restricted to their own barrel, are likely to generate strong disynaptic inhibition in other barrel neurons, both excitatory and inhibitory. Because putative inhibitory barrel neurons often have multiwhisker receptive fields (Simons and Carvell, 1989; Swadlow, 1989; Welker et al., 1993), type A neurons may also mediate the adjacent-whisker inhibition observed in vivo (Simons, 1995; Goldreich et al., 1999). Types B, D, and E neurons, with a sphere of influence extending to layers II/III, probably mediate the strong disynaptic inhibition observed in supragranular neurons in vivo (Ferster and Lindstrom, 1983; Kyriazi et al., 1998; Brumberg et al., 1999; Zhu and Connors, 1999) or in vitro (Agmon and Connors, 1992). Finally, inhibitory neurons of morphological type E, with axonal trees that extend tangentially at least one barrel width on either or both sides of the column of origin, will generate the short-latency cross-column inhibition that is a prominent feature in supragranular layers of mouse barrel cortex in vivo (Welker et al., 1993).

\section{Excitatory and inhibitory flow after a thalamocortical volley}

The overwhelming preponderance of upwardly directed axonal arbors of layer IV interneurons indicates that the flow of inhibition in the barrel cortex, after a thalamocortical volley, will be toward the upper layers. Interestingly, this is also the main direction of flow of excitation mediated by spiny stellate and star pyramidal cells' axons (Lund et al., 1979; Ferster and Lindstrom, 1983; Armstrong-James et al., 1992; Anderson et al., 1994; Lubke et al., 2000). Thus, inhibition in the cortex is inextricably linked to excitation, apparently following it along its intracortical course. This close association between excitatory and inhibitory influences ensures that the most pertinent sensory information will be incorporated into a conscious sensory experience, while other, weaker and potentially distracting, inputs will be suppressed (Welker et al., 1993; Moore and Nelson, 1998), in effect producing a contrast-enhancement operation on the cortical representation of the sensory environment.

\section{REFERENCES}

Agmon A, Connors BW (1991) Thalamocortical responses of mouse somatosensory (barrel) cortex in vitro. Neuroscience 41:365-379.

Agmon A, Connors BW (1992) Correlation between intrinsic firing patterns and thalamocortical synaptic responses of neurons in mouse barrel cortex. J Neurosci 12:319-329.

Agmon A, Yang LT, O’Dowd DK, Jones EG (1993) Organized growth of thalamocortical axons from the deep tier of terminations into layer IV of developing mouse barrel cortex. J Neurosci 13:5365-5382.

Agmon A, Hollrigel G, O’Dowd DK (1996) Functional GABAergic synaptic connection in neonatal mouse barrel cortex. $\mathrm{J}$ Neurosci 16:4684-4695.

Alcantara S, de Lecea L, Del Rio JA, Ferrer I, Soriano E (1996) Transient colocalization of parvalbumin and calbindin D28k in the postnatal cerebral cortex: evidence for a phenotypic shift in developing nonpyramidal neurons. Eur J Neurosci 8:1329-1339.

Anderson JC, Douglas RJ, Martin KA, Nelson JC (1994) Synaptic output of physiologically identified spiny stellate neurons in cat visual cortex. J Comp Neurol 341:16-24.

Angulo MC, Lambolez B, Audinat E, Hestrin S, Rossier J (1997) Subunit composition, kinetic, and permeation properties of AMPA receptors in single neocortical nonpyramidal cells. J Neurosci 17:6685-6696. 
Armstrong-James M, Fox K, Das-Gupta A (1992) Flow of excitation within rat barrel cortex on striking a single vibrissa. J Neurophysiol 68:1345-1358.

Azouz R, Gray CM, Nowak LG, McCormick DA (1997) Physiological properties of inhibitory interneurons in cat striate cortex. Cereb Cortex 7:534-545.

Beierlein M, Gibson JR, Connors BW (2000) A network of electrically coupled interneurons drives synchronized inhibition in neocortex. Nat Neurosci 3:904-910.

Brumberg JC, Pinto DJ, Simons DJ (1996) Spatial gradients and inhibitory summation in the rat whisker barrel system. J Neurophysiol 76:130-140.

Brumberg JC, Pinto DJ, Simons DJ (1999) Cortical columnar processing in the rat whisker-to-barrel system. J Neurophysiol 82:1808-1817.

Cauli B, Audinat E, Lambolez B, Angulo MC, Ropert N, Tsuzuki K, Hestrin S, Rossier J (1997) Molecular and physiological diversity of cortical nonpyramidal cells. J Neurosci 17:3894-3906.

Celio MR (1986) Parvalbumin in most gamma-aminobutyric acidcontaining neurons of the rat cerebral cortex. Science 231:995-997.

Cobas A, Welker E, Fairen A, Kraftsik R, Van der Loos H (1987) GABAergic neurons in the barrel cortex of the mouse: an analysis using neuronal archetypes. J Neurocytol 16:843-870.

Dantzker JL, Callaway EM (2000) Laminar sources of synaptic input to cortical inhibitory interneurons and pyramidal neurons. Nat Neurosci 3:701-707.

del Rio JA, de Lecea L, Ferrer I, Soriano E (1994) The development of parvalbumin-immunoreactivity in the neocortex of the mouse. Brain Res Dev Brain Res 81:247-259.

Dykes RW, Landry P, Metherate R, Hicks TP (1984) Functional role of GABA in cat primary somatosensory cortex: shaping receptive fields of cortical neurons. J Neurophysiol 52:1066-1093.

Fairén A (1993) Axonal patterns of interneurons in the cerebral cortex: in memory of Rafael Lorente de No. In: The mammalian cochlear nuclei: organization and function (Merchan MA, Juiz JM, Godfried DA, Mugnaini E, eds), pp 467-478. New York: Plenum.

Fairén A, Valverde F (1979) Specific thalamo-cortical afferents and their presumptive targets in the visual cortex. A Golgi study. Prog Brain Res 51:419-438.

Ferster D, Lindstrom S (1983) An intracellular analysis of geniculocortical connectivity in area 17 of the cat. J Physiol (Lond) 342:181-215.

Freund TF, Martin KA, Somogyi P, Whitteridge D (1985) Innervation of cat visual areas 17 and 18 by physiologically identified X-and Y-type thalamic afferents. II. Identification of postsynaptic targets by GABA immunocytochemistry and Golgi impregnation. J Comp Neurol 242:275-291.

Galarreta M, Hestrin S (1999) A network of fast-spiking cells in the neocortex connected by electrical synapses. Nature 402:72-75.

Gibson JR, Beierlein M, Connors BW (1999) Two networks of electrically coupled inhibitory neurons in neocortex. Nature 402:75-79.

Gil Z, Amitai Y (1996) Properties of convergent thalamocortical and intracortical synaptic potentials in single neurons of neocortex. J Neurosci 16:6567-6578.

Goldreich D, Kyriazi HT, Simons DJ (1999) Functional independence of layer IV barrels in rodent somatosensory cortex. J Neurophysiol 82:1311-1316.

Good PI (1999) Resampling methods. Boston: Birkhauser.

Gupta A, Wang Y, Markram H (2000) Organizing principles for a diversity of GABAergic interneurons and synapses in the neocortex. Science 287:273-278.

Hendry SH, Jones EG, Emson PC, Lawson DE, Heizmann CW, Streit P (1989) Two classes of cortical GABA neurons defined by differential calcium binding protein immunoreactivities. Exp Brain Res 76:467-472.

Hicks TP, Dykes RW (1983) Receptive field size for certain neurons in primary somatosensory cortex is determined by GABA-mediated intracortical inhibition. Brain Res 274:160-164.

Hirsch JA (1995) Synaptic integration in layer IV of the ferret striate cortex. J Physiol (Lond) 483:183-199.

Houser CR, Hendry SH, Jones EG, Vaughn JE (1983) Morphological diversity of immunocytochemically identified GABA neurons in the monkey sensory-motor cortex. J Neurocytol 12:617-638.

Johnston D, Wu SM (1995) Dendritic spines and their effects on synaptic inputs. In: Foundations of cellular neurophysiology, pp 400-411. Cambridge, MA: MIT.

Jones EG, Hendry SH (1984) Basket cells. In: Cellular components of the cerebral cortex (Peters A, Jones EG, eds), pp 309-336. New York: Plenum.

Kawaguchi Y (1993) Groupings of nonpyramidal and pyramidal cells with specific physiological and morphological characteristics in rat frontal cortex. J Neurophysiol 69:416-431.

Kawaguchi Y (1995) Physiological subgroups of nonpyramidal cells with specific morphological characteristics in layer II/III of rat frontal cortex. J Neurosci 15:2638-2655.

Kawaguchi Y, Kubota Y (1993) Correlation of physiological subgroupings of nonpyramidal cells with parvalbumin- and calbindin D28k- immunoreactive neurons in layer $\mathrm{V}$ of rat frontal cortex. J Neurophysiol 70:387-396

Kawaguchi Y, Kubota Y (1997) GABAergic cell subtypes and their synaptic connections in rat frontal cortex. Cereb Cortex 7:476-486.

Keller A, White EL (1987) Synaptic organization of GABAergic neurons in the mouse SmI cortex. J Comp Neurol 262:1-12.

Kharazia VN, Weinberg RJ (1993) Glutamate in terminals of thalamocortical fibers in rat somatic sensory cortex. Neurosci Lett 157:162-166.

Kisvarday ZF, Gulyas A, Beroukas D, North JB, Chubb IW, Somogyi P (1990) Synapses, axonal and dendritic patterns of GABAimmunoreactive neurons in human cerebral cortex. Brain 113:793-812.

Koch C (1999) Dendritic spines. In: Biophysics of computation, pp 280307. New York: Oxford UP.

Kyriazi H, Carvell GE, Brumberg JC, Simons DJ (1998) Laminar differences in bicuculline methiodide's effects on cortical neurons in the rat whisker/barrel system. Somatosens Mot Res 15:146-156.

Kyriazi HT, Carvell GE, Brumberg JC, Simons DJ (1996) Effects of baclofen and phaclofen on receptive field properties of rat whisker barrel neurons. Brain Res 712:325-328.

Lin CS, Lu SM, Schmechel DE (1985) Glutamic acid decarboxylase immunoreactivity in layer IV of barrel cortex of rat and mouse. J Neurosci 5:1934-1939.

Lorente de Nó R (1992) The cerebral cortex of the mouse (a first contribution-the "acoustic" cortex). Somatosens Mot Res 9:3-36. (English translation of the original 1922 paper, translated by Fairén A, Regidor J, and Kruger L).

Lubke J, Egger V, Sakmann B, Feldmeyer D (2000) Columnar organization of dendrites and axons of single and synaptically coupled excitatory spiny neurons in layer 4 of the rat barrel cortex. J Neurosci 20:5300-5311.

Lund JS, Henry GH, MacQueen CL, Harvey AR (1979) Anatomical organization of the primary visual cortex (area 17) of the cat. A comparison with area 17 of the macaque monkey. J Comp Neurol 184:599-618.

Maier DL, McCasland JS (1997) Calcium-binding protein phenotype defines metabolically distinct groups of neurons in barrel cortex of behaving hamsters. Exp Neurol 145:71-80.

McCasland JS, Hibbard LS (1997) GABAergic neurons in barrel cortex show strong, whisker-dependent metabolic activation during normal behavior. J Neurosci 17:5509-5527.

McCormick DA, Connors BW, Lighthall JW, Prince DA (1985) Comparative electrophysiology of pyramidal and sparsely spiny stellate neurons of the neocortex. J Neurophysiol 54:782-806.

Moore CI, Nelson SB (1998) Spatio-temporal subthreshold receptive fields in the vibrissa representation of rat primary somatosensory cortex. J Neurophysiol 80:2882-2892.

Nie F, Wong-Riley MT (1995) Double labeling of GABA and cytochrome oxidase in the macaque visual cortex: quantitative EM analysis. J Comp Neurol 356:115-131.

Peters A, Kara DA (1985a) The neuronal composition of area 17 of rat visual cortex. I. The pyramidal cells. J Comp Neurol 234:218-241.

Peters A, Kara DA (1985b) The neuronal composition of area 17 of rat visual cortex. II. The nonpyramidal cells. J Comp Neurol 234:242-263.

Peters A, Feldman M, Saldanha J (1976) The projection of the lateral geniculate nucleus to area 17 of the rat cerebral cortex. II. Terminations upon neuronal perikarya and dendritic shafts. J Neurocytol 5:85-107.

Porter JT, Cauli B, Tsuzuki K, Lambolez B, Rossier J, Audinat E (1999) Selective excitation of subtypes of neocortical interneurons by nicotinic receptors. J Neurosci 19:5228-5235.

Prieto JJ, Peterson BA, Winer JA (1994) Morphology and spatial distribution of GABAergic neurons in cat primary auditory cortex (AI). J Comp Neurol 344:349-382.

Ren JQ, Aika Y, Heizmann CW, Kosaka T (1992) Quantitative analysis of neurons and glial cells in the rat somatosensory cortex, with special reference to GABAergic neurons and parvalbumin-containing neurons. Exp Brain Res 92:1-14.

Reyes A, Lujan R, Rozov A, Burnashev N, Somogyi P, Sakmann B (1998) Target-cell-specific facilitation and depression in neocortical circuits. Nat Neurosci 1:279-285.

Sanchez MP, Frassoni C, Alvarez-Bolado G, Spreafico R, Fairen A (1992) Distribution of calbindin and parvalbumin in the developing somatosensory cortex and its primordium in the rat: an immunocytochemical study. J Neurocytol 21:717-736.

Sillito AM (1975) The contribution of inhibitory mechanisms to the receptive field properties of neurones in the striate cortex of the cat. J Physiol (Lond) 250:305-329.

Sillito AM, Kemp JA, Milson JA, Berardi N (1980) A re-evaluation of the mechanisms underlying simple cell orientation selectivity. Brain Res 194:517-520.

Simons DJ (1978) Response properties of vibrissa units in rat SI somatosensory neocortex. J Neurophysiol 41:798-820.

Simons DJ (1995) Neuronal integration in the somatosensory whisker/ barrel cortex. In: Cerebral cortex (Jones EG, Diamond IT, eds), pp 263-297. New York: Plenum. 
Simons DJ, Carvell GE (1989) Thalamocortical response transformation in the rat vibrissa/barrel system. J Neurophysiol 61:311-330.

Simons DJ, Woolsey TA (1984) Morphology of Golgi-Cox-impregnated barrel neurons in rat SmI cortex. J Comp Neurol 230:119-132.

Somogyi P (1977) A specific "axo-axonal" interneuron in the visual cortex of the rat. Brain Res 136:345-350.

Staiger JF, Zilles K, Freund TF (1996) Distribution of GABAergic elements postsynaptic to ventroposteromedial thalamic projections in layer IV of rat barrel cortex. Eur J Neurosci 8:2273-2285.

Stuart GJ, Dodt HU, Sakmann B (1993) Patch-clamp recordings from the soma and dendrites of neurons in brain slices using infrared video microscopy. Pflügers Arch 423:511-518.

Swadlow HA (1989) Efferent neurons and suspected interneurons in S-1 vibrissa cortex of the awake rabbit: receptive fields and axonal properties. J Neurophysiol 62:288-308.

Swadlow HA (1990) Efferent neurons and suspected interneurons in S-1 forelimb representation of the awake rabbit: receptive fields and axonal properties. J Neurophysiol 63:1477-1498.

Swadlow HA, Gusev AG (2000) The influence of single VB thalamocortical impulses on barrel columns of rabbit somatosensory cortex. J Neurophysiol 83:2802-2813.

Swadlow HA, Beloozerova IN, Sirota MG (1998) Sharp, local synchrony among putative feed-forward inhibitory interneurons of rabbit somatosensory cortex. J Neurophysiol 79:567-582.

Swanson GT, Kamboj SK, Cull-Candy SG (1997) Single-channel properties of recombinant AMPA receptors depend on RNA editing, splice variation, and subunit composition. J Neurosci 17:58-69.

Tamas G, Buhl EH, Somogyi P (1997a) Fast IPSPs elicited via multiple synaptic release sites by different types of GABAergic neurone in the cat visual cortex. J Physiol (Lond) 500:715-738.

Tamas G, Buhl EH, Somogyi P (1997b) Massive autaptic selfinnervation of GABAergic neurons in cat visual cortex. J Neurosci $17: 6352-6364$
Tamas G, Somogyi P, Buhl EH (1998) Differentially interconnected networks of GABAergic interneurons in the visual cortex of the cat. J Neurosci 18:4255-4270.

Thomson AM, West DC, Hahn J, Deuchars J (1996) Single axon IPSPs elicited in pyramidal cells by three classes of interneurones in slices of rat neocortex. J Physiol (Lond) 496:81-102.

Tsumoto T, Eckart W, Creutzfeldt OD (1979) Modification of orientation sensitivity of cat visual cortex neurons by removal of GABAmediated inhibition. Exp Brain Res 34:351-363.

Welker E, Armstrong-James M, Van der Loos H, Kraftsik R (1993) The mode of activation of a barrel column: response properties of single units in the somatosensory cortex of the mouse upon whisker deflection. Eur J Neurosci [Erratum (1993) 5:1421] 5:691-712.

White EL (1978) Identified neurons in mouse Sml cortex which are postsynaptic to thalamocortical axon terminals: a combined Golgielectron microscopic and degeneration study. J Comp Neurol 181:627-661.

White EL, Rock MP (1981) A comparison of thalamocortical and other synaptic inputs to dendrites of two non-spiny neurons in a single barrel of mouse SmI cortex. J Comp Neurol 195:265-277.

White EL, Benshalom G, Hersch SM (1984) Thalamocortical and other synapses involving nonspiny multipolar cells of mouse SmI cortex. J Comp Neurol 229:311-320.

Woolsey TA, Van der Loos H (1970) The description of a cortical field composed of discrete cytoarchitectonic units. Brain Res 17:205-242.

Xiang Z, Huguenard JR, Prince DA (1998) Cholinergic switching within neocortical inhibitory networks. Science 281:985-988.

Yamamoto T, Samejima A, Oka H (1988) Short latency activation of local circuit neurons in the cat somatosensory cortex. Brain Res 461:199-203.

Zhu JJ, Connors BW (1999) Intrinsic firing patterns and whisker-evoked synaptic responses of neurons in the rat barrel cortex. J Neurophysiol 81:1171-1183. 